\title{
UNA NUEVA ESPECIE DE YUCCA (AGAVACEAE) DE OAXACA Y PUEBLA, MEXICO
}

\author{
Abisal Garcia-Mendoza \\ Jardín Botánico \\ Instituto de Biología, UNAM \\ Apartado postal $70-614$ \\ 04510 México, D.F.
}

\begin{abstract}
RESUMEN
Se describe e ilustra Yucca mixtecana sp. nov., de la región limítrofe entre los estados de Oaxaca y Puebla, México. La especie pertenece a la sección Sarcocarpa Engelm., serie Treculeanae McKelvey, y muestra similitudes con $Y$. periculosa Baker y $Y$. jaliscensis Trel.
\end{abstract}

\begin{abstract}
Yucca mixtecana sp. nov. is described from near the border between the Mexican states of Oaxaca and Puebla. The species is a member of section Sarcocarpa Engelm., series Treculeanae McKelvey. It is similar to $Y$. periculosa Baker and $Y$. jaliscensis Trel.

El género Yucca, de distribución americana, consiste de 46 especies (Clary, 1997), 30 de las cuales crecen en México (Espejo y López-Ferrari, 1992; García-Mendoza y Galván, 1995). Para el Valle de Tehuacán y las montañas de la Mixteca Alta (límites entre los estados de Oaxaca y Puebla) sólo se tenía registro de Yucca periculosa Baker (Matuda y Piña, 1980). Como parte del estudio taxonómico de las Agavaceae para esta región se encontraron especímenes que representan una nueva especie para la ciencia.

Yucca mixtecana García-Mend., sp. nov. Fig. 1.

Planta arborescens ad $4 \mathrm{~m}$ alta; caules graciles, conici, vix ramosi. Folia $40-65(-75) \mathrm{cm}$ longa, $1.5-3 \mathrm{~cm}$ lata, glauca, flexilia, mox caduca. Panicula erecta, $50-80 \mathrm{~cm}$ longa, ramulis $10-20 \mathrm{~cm}$ longis, pilosulis, $15-20$ floribus per ramulum. Flores $(1.5-) 2-2.5(-3) \mathrm{cm}$ longi; fructus cylindrici, $5-8 \mathrm{~cm}$ longi, $2-2.5 \mathrm{~cm}$ lati.

Plantas policárpicas, arborescentes, con el tallo simple o ramificado en la parte superior, formando colonias rizomatosas, a menudo de 10-25 individuos. Tallos de 2.5-5 m de alto, más o menos cónicos, esbeltos, con placas en la corteza de forma irregular. Hojas de $40-65(-75) \mathrm{cm}$ de largo por $1.5-3 \mathrm{~cm}$ de ancho en su porción media, angostándose a $1-2 \mathrm{~cm}$ en la base, linear-lanceoladas o lineares, erectas, glaucas a verde-amarillentas, cuando secas caedizas; margen entero, con una banda de color oscuro, filífero, hilos finos y suaves; espina terminal de $0.5-1 \mathrm{~cm}$ de largo, parda oscura, acanalada en el haz. Panícula de 50-80 cm de largo, moderadamente ramificada, erecta; pedúnculo de $20-30 \mathrm{~cm}$
\end{abstract}




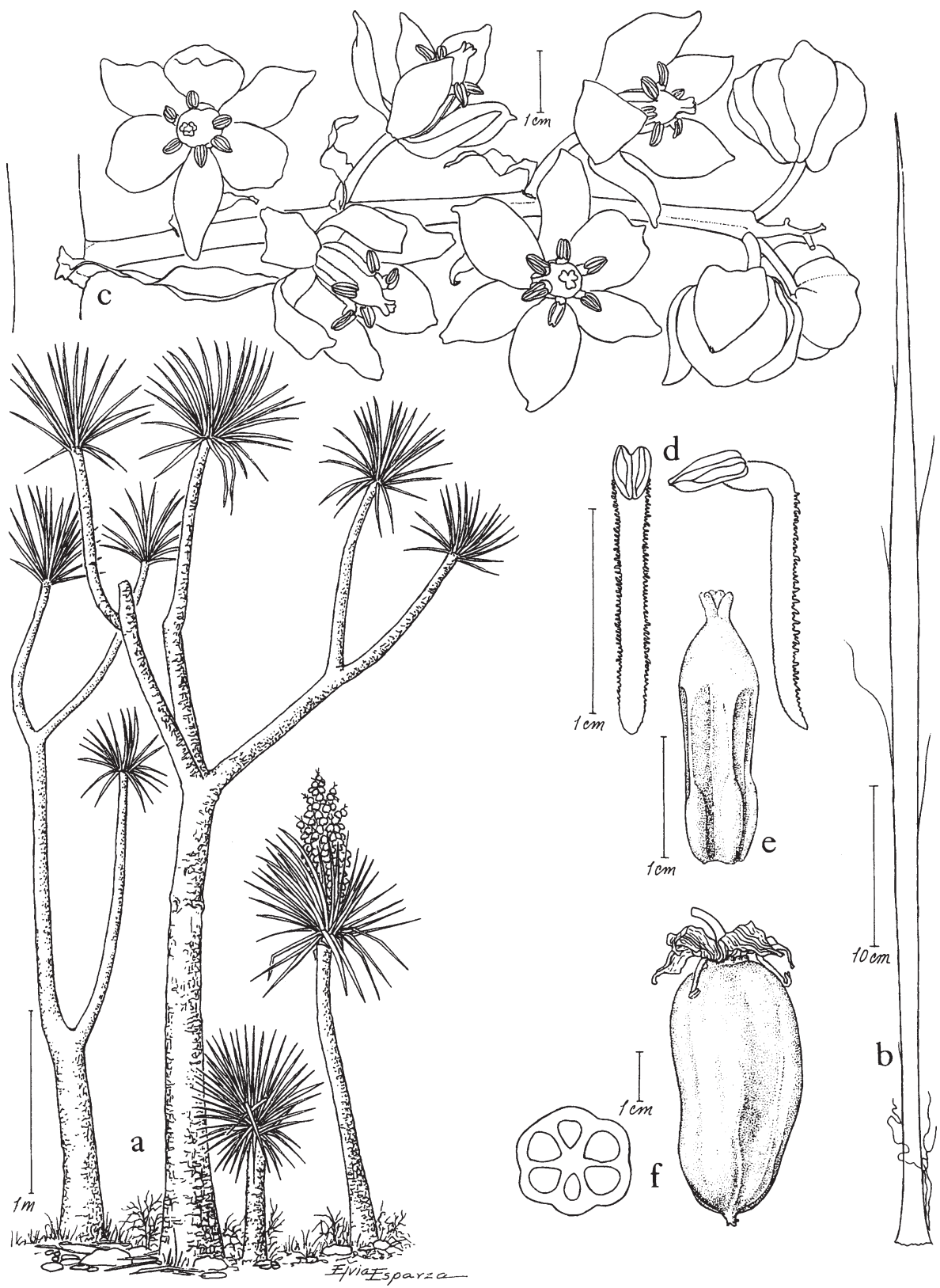

Fig. 1. Yucca mixtecana Garcia-Mend. a. Plantas completas; b. Hoja; c. Ramilla floral; d. Estambre; e. Estilo; f. Fruto completo y sección transversal del mismo. Basado en los ejemplares GarcíaMendoza 6043, 6198. 
de largo, pilósulo; ramillas de la inflorescencia en la parte media (las más largas) de 10-20 cm de largo, pilósulas, con 15-20 flores por ramilla. Flores de (1.5-)2-2.5(-3) cm de largo, campanuladas, péndulas, blanquecinas a amarillentas; pedicelos de (1-)1.5-2 cm, pilósulos; tépalos externos de $2-2.5(-3) \mathrm{cm}$ de largo por $0.4-0.7(-1) \mathrm{cm}$ de ancho, lanceolados, glabros; tépalos internos de $2-2.5(-3) \mathrm{cm}$ de largo por $0.6-1(-1.3) \mathrm{cm}$ de ancho, elípticos, glabros; estambres de $1-1.5(-2) \mathrm{cm}$ de largo, filamentos reflexos en el cuarto superior de su longitud, gradualmente haciéndose más anchos hacia el ápice, con dos líneas de minúsculas láminas translúcidas; anteras de $2-4 \mathrm{~mm}$ de largo, sagitadas; pistilo de $1.5-2(-3) \mathrm{cm}$ de largo, cilíndrico, con suturas carpelares profundas, los tres lóbulos estigmáticos retusos. Frutos carnosos, de $(3-) 5-8 \mathrm{~cm}$ de largo por $2-2.5 \mathrm{~cm}$ de ancho, cilíndricos, péndulos, verdes. Semillas lacrimiformes, negras, con endospermo ruminado.

TIPO: México, Oaxaca, distrito de Coixtlahuaca, municipio de Tepelmeme, 15 km al noroeste de Tepelmeme, carretera Oaxaca-Tehuacán, 1690 m s.n.m., matorral xerófilo con Agave salmiana, Beaucarnea purpusii, Dasylirion lucidum, Hechtia, Bursera, Gochnatia y Opuntia, 26 abril 1996, A. García-Mendoza, A. Gutiérrez y S. Franco 6198 (Holotipo: MEXU, Isotipos: BM, ENCB, MO, OAX, TEX).

Paratipos: México, Oaxaca, dto. de Teposcolula, ruta 190, ca. $10 \mathrm{~km}$ al $\mathrm{NO}$ de Tamazulapan, 11 mayo 1981, R. Cedillo T., D. Lorence y A. García-Mendoza 792 (MEXU); dto. de Teposcolula, cerca de la planta hidroeléctrica de Tamazulapan, orilla de la carretera, 23 marzo 1969, R. Cruz C. 2360 (MEXU); dto. de Coixtlahuaca, mpio. de Tepelmeme, cerro El Ramón, $1 \mathrm{~km}$ al O de El Rodeo, 8 julio 1986, A. García-Mendoza, $P$. Tenorio y A. Salinas 2419 (MEXU); dto. de Teposcolula, río del Oro, $6 \mathrm{~km}$ al NO de Tamazulapan, 13 mayo 1988, A. García-Mendoza, R. Torres y A. Campos 3940 (MEXU); dto. de Coixtlahuaca, $20 \mathrm{~km}$ al $\mathrm{S}$ del puente sobre el río Hondo, carr. Tehuacán-Oaxaca, 29 abril 1995, A. García-Mendoza y F. Martínez 6039 (ENCB, K, MEXU, TEX, UAMIZ); dto. de Coixtlahuaca, $16 \mathrm{~km}$ al NO de Tepelmeme, carr. Oaxaca-Tehuacán, 29 abril 1995, A. García-Mendoza y F. Martínez 6042 (ENCB, K, MEXU, MO, OAX); A. García-Mendoza y F. Martínez 6043 (B, BM, ENCB, MEXU); dto. de Coixtlahuaca, $15 \mathrm{~km}$ al NO de Tepelmeme, carr. Oaxaca-Tehuacán, 26 abril 1996, A. García-Mendoza, A. Gutiérrez y S. Franco 6197 (DES, ENCB, K, MEXU, TEX, XAL); dto. de Teposcolula, $7 \mathrm{~km}$ al O de Tamazulapan rumbo a Huajuapan, 20 marzo 1980, F. González M., V. Jaramillo, P. Dávila y J. L. Villaseñor 637 (MEXU). Puebla, mpio. de Zapotitlán, límite estatal Puebla-Oaxaca, por la carr. Huajuapan de León-Tehuacán, 22 marzo 1980, F. González M., V. Jaramillo, $P$. Dávila y J. L. Villaseñor 723 (MEXU); Zapotitlán, km 55 on road 125 TehuacánHuajuapan, $1 \mathrm{~km}$ from Oaxaca border, S of Acatepec, 23 octubre 1978, B. Leuenberger y C. Schiers 2568 (MEXU); mpio. de Caltepec, $2 \mathrm{~km}$ al NO de Santiago Acatepec, 14 abril 1984, P. Tenorio y C. Romero 5871 (MEXU); mpio. de Caltepec, El Horno, Barranca de la Compañía, 19 mayo 1991, P. Tenorio, C. Romero y F. Tenorio 17357 (MEXU).

Distribución: La nueva especie habita en las montañas de la Mixteca Alta, en los distritos de Coixtlahuaca, Teposcolula y Huajuapan, en el noroeste del estado de Oaxaca, así como en una porción de los municipios de Caltepec y Zapotitlán, en el sur del estado 
Hábitat: Matorrales xerófilos y su transición con la selva baja caducifolia, junto con Agave kerchovei, A. potatorum, A. titanota, A. salmiana, Beaucarnea purpusii, Conzattia multiflora, Dasylirion lucidum, Gochnatia hypoleuca, Bursera, Hechtia, Opuntia y Sedum. También crece en los matorrales esclerófilos con Ceanothus, Coutaportla, Krameria, Rhus, Vauquelinia y Wimmeria. Se le encuentra entre los 1370-2200 m s.n.m., sobre laderas inclinadas con suelos someros y pedregosos.

Discusión: Por presentar frutos abayados, péndulos e indehiscentes y semillas gruesas con albumen ruminado, Yucca mixtecana se ubica dentro de la sección Sarcocarpa, de acuerdo con el criterio de McKelvey (1938-1947); sección con 22 especies, cuya distribución abarca el suroeste de los Estados Unidos y México. McKelvey (1938-1947) subdivide Sarcocarpa en tres series, Faxonianae, Baccatae y Treculeanae; las primeras dos se distinguen por sus largos pistilos, mayores de $4.5 \mathrm{~cm}$ en antesis; además Faxonianae está formada por especies arborescentes, mientras que Baccatae lo está por especies cespitosas con tallos procumbentes o más o menos erectos. La sección Treculeanae la conforman plantas arborescentes con pistilos cortos de menos de $4.5 \mathrm{~cm}$ de largo en antesis y frutos pequeños, menores de $7.5 \mathrm{~cm}$. Yucca mixtecana se ubica en esta serie, junto con otras 16 especies, la mayoría de ellas de distribución mexicana. Se relaciona más con $Y$. periculosa y $Y$. jaliscensis, de las cuales puede separarse según los caracteres mostrados en el Cuadro 1. Y. mixtecana se caracteriza por tener un porte menor al de las otras dos especies, por sus tallos cónicos, delgados y poco ramificados,

Cuadro 1. Caracteres de Yucca mixtecana y especies afines. Los datos de $Y$. jaliscensis fueron tomados de McVaugh (1989).

\begin{tabular}{|c|c|c|c|}
\hline & Y. mixtecana & Y. periculosa & Y. jaliscensis \\
\hline Altura & $2.5-5 \mathrm{~m}$ & hasta de $15 \mathrm{~m}$ & $6-10 m$ \\
\hline Forma del tallo & cónico, delgado & cilindrico, grueso & cilíndrico, grueso \\
\hline Ramificación & escasa & abundante & abundante \\
\hline Hojas & $\begin{array}{c}40-65(-75) \times 1.5-3 \mathrm{~cm} \\
\text { flexibles }\end{array}$ & $\begin{array}{c}50-70 \times 3-3.5 \mathrm{~cm} ; \\
\text { rígidas }\end{array}$ & $\begin{array}{c}(30-) 50-100 \times 4-8 \mathrm{~cm} \\
\text { flexibles }\end{array}$ \\
\hline $\begin{array}{l}\text { Persistencia de las } \\
\text { hojas en el tallo }\end{array}$ & caedizas & persistentes & persistentes \\
\hline Color de las hojas & glaucas & verdes & glaucas \\
\hline Panícula & $50-80 \mathrm{~cm}$; erecta & $\begin{array}{l}80-120 \mathrm{~cm} \text {; erecta o } \\
\text { algo inclinada }\end{array}$ & $\begin{array}{c}50-100 \mathrm{~cm} \text {; erecta o } \\
\text { péndula }\end{array}$ \\
\hline Ramillas & pilósulas & pubescentes a pilosas & $\begin{array}{l}\text { densamente pubes- } \\
\text { centes a canescentes }\end{array}$ \\
\hline Flores & $(1.5-) 2-2.5(-3) \mathrm{cm}$ & (3-)3.5-4.5 cm & $3-4 \mathrm{~cm}$ \\
\hline Frutos & $(3-) 5-8 \times 2-2.5 \mathrm{~cm}$ & $8-10 \times 2-3.5(-5) \mathrm{cm}$ & $7.5-9.5 \times 4-5 \mathrm{~cm}$ \\
\hline
\end{tabular}


por las hojas angostas, caedizas cuando secas, y por sus flores y frutos más pequeños. Su floración se presenta de marzo a mayo y la fructificación de julio a septiembre.

Yucca jaliscensis crece entre los 1000 y 2200 m s.n.m., en selvas bajas caducifolias, bosques de Pinus-Quercus o bien como planta cultivada, en los estados de Jalisco y Nayarit (McVaugh, 1989), mientras que $Y$. periculosa se desarrolla entre los 1600 y 2000 m s.n.m., en diferentes tipos de matorrales xerófilos y selvas bajas caducifolias en los estados de Tlaxcala, Veracruz y Puebla.

\section{AGRADECIMIENTOS}

Agradezco a Patricia Dávila, Raquel Galván y Fernando Chiang sus comentarios al manuscrito; este último elaboró la descripción latina. El dibujo es obra de Elvia Esparza.

\section{LITERATURA CITADA}

Clary, H. K. 1997. Phylogeny, character evolution and biogeography of Yucca L. (Agavaceae) as inferred from plant morphology and sequences of the internal transcribed spacer (ITS) region of the nuclear ribosomal DNA. PhD. Dissertation, University of Texas. Austin, Texas. $214 \mathrm{pp}$. Espejo, A. y A. R. López-Ferrari. 1992. Las Monocotiledóneas mexicanas, una sinopsis florística. 1. Lista de referencia. Parte 1. Agavaceae, Alismaceae, Alliaceae, Alstroemeriaceae y Amaryllidaceae. Consejo Nacional de la Flora de México, A.C. y Universidad Autónoma Metropolitana. México, D.F. pp. 38-43.

García-Mendoza, A. y R. Galván. 1995. Riqueza de las familias Agavaceae y Nolinaceae en México. Bol. Soc. Bot. México 56: 7-24.

Matuda, E. e I. Piña. 1980. Las plantas mexicanas del género Yucca. Colección miscelánea del Estado de México. Toluca. $145 \mathrm{pp}$.

McKelvey, S. D. 1938-1947. Yuccas of the Southwestern United States. Arnold Arboretum of Harvard Univ. Jamaica Plains, Mass. $192 \mathrm{pp}$.

McVaugh, R. 1989. Yucca. In: Anderson W. R. (ed.). Flora Novo-Galiciana; a descriptive account of the vascular plants of western Mexico. Vol. 15. Bromeliaceae to Dioscoreaceae. pp. 281-283. 